Info Artikel

Diterima : 24 Juni 2020

Direvisi : 13 Januari 2021

Disetujui : 31 Januari 2021

\title{
Nilai-Nilai Karakter dalam Novel Maryamah Karpov: Mimpi-Mimpi Lintang Karya Andrea Hirata Sebagai Bahan Ajar Novel di SMA
}

\author{
Lita Yolanda Aprilianti ${ }^{1}$, Tati Sri Uswati ${ }^{2}$, Tato Nuryanto ${ }^{3}$ \\ ${ }^{123}$ IAIN Syekh Nurjati Cirebon, Jawa Barat, Indonesia \\ ${ }^{1}$ litayolanda733@gmail.com, ${ }^{2}$ tatisriuswati@gmail.com, ${ }^{3}$ tatonuryanto28@yahoo.com
}

Abstract: The character values in a novel entitled "Maryamah Karpov: Mimpi-Mimpi Lintang" are varied. The purpose of the research is to describe character values and to develop "Maryamah Karpov: Mimpi-Mimpi Lintang" as novel teaching materials in class XII SMA. The method used in analyzing the data is a qualitative descriptive technique. The method used in data collection is content analysis with literature study techniques and questionnaires. The results showed that there are character values in the novel, which include (1) character values in relation to God; (2) character values in relation to oneself; (3) character values in relation to others; (4) character values in relation to the environment and social; and (5) character values in relationship with nationality. The validation results obtained through expert validators are $84.37 \%$ so which is categorized as quite valid and can be used as teaching materials by making light revisions on some details.

Keywords: Teaching materials, handouts, character values, novels

Abstrak : Nilai karakter dalam novel Maryamah Karpov: Mimpi-mimpi Lintang beragam. Tujuan penelitian ini adalah mendeskripsikan nilai-nilai karakter dan mengembangkan novel Maryamah Karpov: Mimpi-mimpi Lintang sebagai bahan ajar novel di kelas XII SMA. Metode yang digunakan dalam menganalisis data adalah dengan teknik deskriptif kualitatif. Metode yang digunakan dala pengumpulan data yaitu metode analisis isi dengan teknik studi pustaka dan angket. Hasil penelitian menunjukkan bahwa novel Maryamah Karpov: Mimpimimpi Lintang Karya Andrea Hirata terdapat nilai karakter dalam hubungannya dengan Tuhan, nilai karakter dalam hubungannya dengan diri sendiri, nilai karakter dalam hubungannya dengan sesama, nilai karakter dalam hubungannya dengan lingkungan dan sosial serta nilai karakter dalam hubungannya dengan kebangsaan. Hasil validasi yang telah dilakukan oleh validator ahli sebesar $84,37 \%$ sehingga dapat dikatakan termasuk dalam kategori cukup valid dan dapat digunakan namun perlu direvisi kecil sebagai bahan ajar.

Kata Kunci : Bahan ajar, handout, nilai karakter, novel

http://ejournal.iainbengkulu.ac.id/index.php/disastra

Copyright ( $) 2021$ Disastra: Jurnal Pendidikan Bahasa dan Sastra Indonesia

All rights reserved 
Pendahuluan

Pendidikan Indonesia saat ini menggunakan kurikulum 2013 yang penerapannya menekankan pada penanaman karakter siswa sejak usia dini. Munculnya kasus di kalangan siswa, seperti tawuran pelajar, maraknya korupsi di kalangan pejabat negara, dan kasus semacamnya membuat pemerintah merancang dan menerapkan kurikulum baru. Pendidikan di Indonesia dianggap belum bisa membentuk karakter siswa untuk memiliki perilaku yang sesuai dengan norma. Oleh karena itu, sejak tahun 2013 pemerintah membuat kurikulum 2013 diharapkan ketika diterapkan akan mengubah dan membentuk karakter siswa yang kurang nilai karakternya pada saat itu.

Nilai karakter religius dan kedisiplinan akhir-akhir ini sering menjadi pembahasan di berbagai kalangan media. Siswa sebagai produk pendidikan belum tertanam secara kuat mengenai nilai karakter religius serta kepribadiannya masih lemah sehingga dengan mudah dipengaruhi hal dari luar. Selain itu, semangat untuk belajar, berdisiplin, beretika, dan bekerja keras kian menurun. Peserta didik banyak yang tidak siap untuk menghadapi kehidupan sehingga dengan mudah meniru budaya luar yang negatif (Elfindri, 2014: 98).

Untuk membangun karakter bisa dilakukan dengan berbagai cara. Karakter bukan sesuatu yang sudah ada dari sananya. Namun, karakter merupakan sesuatu yang bisa dibangun dan dibentuk melalui proses. Salah satu cara yang efektif membangun karakter, yaitu dengan disiplin. Penanaman disiplin ini bisa dipandu oleh orang dewasa, seperti orang tua atau guru untuk dijadikan contoh.

Kehidupan menyimpan nilai-nilai karakter yang begitu kaya. Nilai karakter
Volume 3, Nomor 1, Januari 2021

ISSN 2655-3031 (P), 2655-7851 (O)

DOI: http://dx.doi.org/10.29300/disastra.v3i1.3306

menjadi tempat dalam menghimpun nilainilai keluhuran umat manusia yang terhimpun dari agama, budaya, adat-istiadat, kearifan lokal, dan sebagainya (Jamaris, 2013: 35). Karya sastra dijadikan sebagai salah satu media yang dapat digunakan untuk menanamkan nilai kemanusiaan atau yang disebut pendidikan karakter. Sastra sebagai hasil gagasan pikiran seseorang terhadap lingkungan masyarakat, yang mempunyai permasalahan masyarakat diterapkan menggunakan bahasa yang indah. Karya sastra sebagai cerminan kehidupan bermasyarakat yang dapat memberi siswa sebuah gambaran baru yang mungkin belum mereka kenali.

Dengan mengapresiasi karya sastra, siswa dapat menerapkan hikmah yang terkandung di dalamnya pada kehidupan nyata. Novel menjadi media sastra yang baik dalam mengajarkan nilai karakter karena terdiri atas alur cerita yang cukup panjang dan menggambarkan perkembangan tokoh dengan cukup detail (Nurgiyantoro, 2015: 25). Salah satu hasil karya sastra yang terlengkap, yaitu novel.

Novel bukan hanya khayalan pengarang tetapi juga hasil perenungan dan kreativitas yang berawal dari pengalaman, baik pengalaman lahir maupun batin. Pengalaman ini disusun secara kreatif, imajinatif, sistematis, dan estetis dengan menggunakan bahasa sebagai medianya. Sebagai karya kreatif yang bersifat imajinatif, novel tidak hanya diharapkan dapat memberi hiburan, tetapi juga diharapkan dapat memberi manfaat bagi pembaca melalui nilai-nilai yang diusungnya.

Adapun produk-produk yang dihasilkan dalam penelitian ini antara lain materimateri penelitian guru, materi belajar untuk 
peserta didik, media pembelajaran untuk memudahkan belajar, sistem pembelajaran dan lain-lain. Bahan ajar memiliki beragam jenis, ada yang cetak maupun noncetak. Bahan ajar cetak yang sering dijumpai antara lain berupa handout, buku, modul, brosur, dan lembar kerja siswa. Sementara itu Nana Sudjana (2015: 55) memaknai handout sebagai selembar atau beberapa lembar kertas yang berisi tugas atau tes yang diberikan pendidik kepada peserta didik. Dengan kata lain apabila pendidik membuat ringkasan suatu topik, makalah suatu topik, lembar kerja siswa, petunjuk praktikum, tugas, dan diberikan kepada peserta didik secara terpisah-pisah tidak menjadi suatu kumpulan lembar kerja siswa, maka pengemasan materi pembelajaran tersebut termasuk dalam kategori handout.

\section{Metode Penelitian}

Jenis penelitian ini adalah penelitian kualitatif, yaitu penelitian yang menggunakan prosedur pemecahan masalah dan tidak menggunakan perhitungan (Anwar, 2015: 22). Dalam penelitian ini data yang akan digunakan bebentuk kata, kalimat, wacana, serta teks, yang menggambarkan dan menjelaskan nilai-nilai karakter yang terdapat dalam novel Maryamah Karpov: Mimpi-mimpi Lintang karya Andrea Hirata. Jadi, dalam hal ini peneliti mendekatkan diri kepada objek secara utuh.

Tempat yang digunakan dalam penelitian ini tidak terkait pada suatu tempat, karena objek yang dikaji dalam penelitian ini berupa novel. Metode pengumpulan data menggunakan metode analisis isi, dengan dua teknik studi pustaka dan teknik angket. Keabsahan data yang digunakan dalam penelitian ini adalah teknik triangulasi. Moleong (2014: 330-332) menjelaskan bahwa teknik triangulasi merupakan teknik pemeriksaan keabsahan data yang memanfaatkan sesuatu yang lain.

Instrumen penelitian digunakan untuk mengumpulkan data. Instrumen merupakan pedoman dan fasilitas untukmendapatkan datayang tepat dan akurat. Sanjaya (2016:74) menjelaskan bahwa instrumen penelitian adalah alat yang digunakan untuk mengumpulkan data penelitian. Instrumen penelitian yang digunakan yaitu instrumen analisis nilai karakter dalam novel dan instrumen validasi bahan ajar.

Teknik analisis data yang digunakan yaitu metode deskriptif karena data yang akan diuraikan berupa kata-kata. Sugiyono, (2015: 337-347) menjelaskan bahwa aktivitas dalam analisis data kualitatif dilakukan secara interaktif dan langsung terus menerus sehingga datanya jenuh.

\section{Hasil dan Pembahasan}

Berdasarkan hasil penelitian terdapat beberapa nilai karakter yang terkandung dalam novel Maryamah Karpov: Mimpimimpi Lintang karya Andrea Hirata. Dalam analisis ini secara spesifik akan dibahas mengenai isi kandungan nilai-nilai karakter. Hasil penelitian menemukan beberapa data yang akan dibahas dalam skripsi ini, diantaranya: 1) analisis nilai-nilai karakter yang terdapat dalam novel Maryamah Karpov: Mimpi-mimpi Lintang karya Andrea Hirata 2) pengembangan novel Maryamah Karpov: Mimpi-mimpi Lintang karya Andrea Hirata sebagai bahan ajar novel di SMA.

Novel Maryamah Karpov: Mimpimimpi Lintang karya Andrea Hirata dapat dijadikan sebagai bahan ajar novel karena di dalamnya terdapat kalimat-kalimat yang

Lita Yolanda Aprilianti, Tati Sri Uswati, Tato Nuryanto

Nilai-Nilai Karakter dalam Novel Maryamah Karpov: Mimpi-Mimpi Lintang Karya Andrea Hirata Sebagai Bahan Ajar Novel di SMA 
mengandung motivasi dan terdapat makna tersirat maupun tersurat. Selain itu kisah yang terdapat dalam novel Maryamah Karpov: Mimpi-mimpi Lintang karya Andrea Hirata memunculkan situasi baru yang menarik bagi peseta didik, serta merupakan bacaan yang memiliki kisah romansa berbalut pendidikan, sehingga dapat digunakan sebagai bacaan wajib bagi peserta didik.

Hasil analisis ini diharapkan dapat mendeskripsikan niali-nilai karakter yang terkandung dalalam novel Maryamah Karpov: Mimpi-mimpi Lintang karya Andrea Hirata. Kemudian untuk menemukan niali-nilai karakter tersebut, peneliti megadopsi teori dari Gunawan (2013: 31).

\section{Tabel 1 Wujud Nilai Karakter Pada} Novel Maryamah Karpov: Mimpi-mimpi Lintang Karya Andrea Hirata

\begin{tabular}{|l|l|c|}
\hline No & Jenis Nilai Karkter & Jumlah \\
\hline $\mathbf{1}$ & $\begin{array}{l}\text { Nilai Karakter yang } \\
\text { Berhubungan dengan } \\
\text { Tuhan }\end{array}$ & $\mathbf{1 6}$ \\
\hline $\mathbf{2}$ & $\begin{array}{l}\text { Nilai Karakter yang } \\
\text { Berhubungan dengan } \\
\text { Diri Sendiri }\end{array}$ & $\mathbf{2 1}$ \\
\hline $\mathbf{3}$ & $\begin{array}{l}\text { Nilai Karkter yang } \\
\text { Berhubungan dengan } \\
\text { Sesama }\end{array}$ & $\mathbf{1 3}$ \\
\hline $\mathbf{4}$ & $\begin{array}{l}\text { Nilai Karakter yang } \\
\text { Berhubungan dengan } \\
\text { Lingkungan dan Sosial }\end{array}$ & $\mathbf{4}$ \\
\hline $\mathbf{5}$ & $\begin{array}{l}\text { Nilai Karkter yang } \\
\text { Berhubungan dengan } \\
\text { Kebangsaan }\end{array}$ & $\mathbf{6}$ \\
\hline
\end{tabular}

Analisis nilai karakter yang berhubungan dengan Tuhan dalam novel Maryamah Karpov: Mimpi-Mimpi Lintang Karya Andrea Hirata sebagai berikut.
Ayah ikal melakukan kegiatan rutinnya dengan melaksanakan kewajiban salat subuh terlebih dahulu, tak lupa beliau melanjutkan dengan mengaji. Setelah kewajiban semuanya telah dilaksanakan, ayah Ikal duduk bersantai dikursi goyang sambil mendengarkan siaran radio dari Malaysia. Kadang tombol tuning radio kecil diputar ayah menuju Hilversum, Holland, atau menuju London. Ikal mengintip dari kejauahan, terdiam dan tetarik mendengarkan musik dari negara yang jauh. Hal tersebut dapat dilihat pada kutipan di bawah ini.

(RG1) "Ritual rutin Ayah, sesudah salat subuh dan mengaji, ia duduk di kursi goyang sambil mendengar siaran radio Malaysia." (hal 7)

Pada kutipan di atas terdapat nilai karakter yang berhubungan dengan Tuhan. Hal tersebut dibuktikan oleh ayah Ikal, dalam kegiatan sehari-harinya beliau selalu melaksanakan salat subuh, kemudian dilanjut dengan melantunkan ayat suci AlQur'an. Sesungguhnya salat merupakan jalan bagi kita untuk mendekatkan diri kepada Allah Swt, dan merupakan ibadah yang wajib dijalankan. Salat dapat mencegah sifat keji dan munafik serta terhindar dari hal-hal buruk. Setelah semua kewajiban dilaksanakan, ayah Ikal bersantai duduk di kursi goyang sambil mendengarkan siaran radio dari Malaysia. Kegiatan ini setiap hari dilakukan beliau.

Analisis nilai karakter yang berhubungan dengan diri sendiri dalam novel Maryamah Karpov: Mimpi-Mimpi Lintang Karya Andrea Hirata sebagai berikut. 
Ikal menuju ruang sidang yang terletek di ujung dalam bangunan yang terpisah, layaknya paviliun. Atapnya yang menjulang ke atas mirip greja. Lantainya mozaik dan eksotis. Motif lantai atau kaca warna bernada serupa selalu ditemui di lembagalembaga kaum intelek Prancis, sebagai rasa hormat pada para cendekiawan masa lampau. Bahkan bangku kayu rastik di dalam ruangan sidang diletakkan menghadap ke arah pintu tinggi ruang sidang. Pintu itu terbuat dari kayu yang berasal daru hutan Finlandia, hitam berwibawa dan besar. Benda-benda yang berada di ruang sidang inilah yang membuat Ikal semangat belajar. Karena Ikal beranggapan ketika sudah memasuki rung sidang tak ada sanda gurau yang dilakukannya. Hal tersebut dapat terlihat pada kutipan di bawah ini.

(RR1) "Benda-benda itu selalu membuatku rakin belajar. Karena mereka menghembuskan aroma bahwa tempatku akan disidang nanti bukanlah tempat bersanda gurau seperti yang kulakukan dalam kebanyakan waktu hidupku." (hal 20)

Berdasarkan kutipan diatas terdapat nilai karakter yang berhubungan dengan diri sendiri. Hal tersebut terlihat dari ikal yang sangat termotivasi terhadap benda-benda yang berada di ruang sidang, membuat dirinya sangat rajin belajar untuk menghadapi sidang. Karena, saat melaksanakan sidang ujian tidak bisa bercanda seperti kebanyakan dirinya selama menghabiskan waktu hidupnya.

Analisis nilai karakter yang berhubungan dengan sesama dalam novel
Volume 3, Nomor 1, Januari 2021

ISSN 2655-3031 (P), 2655-7851 (O)

DOI: http://dx.doi.org/10.29300/disastra.v3i1.3306
Maryamah Karpov: Mimpi-Mimpi Lintang Karya Andrea Hirata sebagai berikut.

Orang Melayu berbondong-bondong menonton paling depan dan tertawa senang melihat penempilan karakter komedian yang terampil memainkan atraksi api obor. Tawa mereka tentu saja ditambah dengan komentar tentang pakaian sang komedian, tentang caranya memainkan obor, dan tentang kesalahan-kesalahan kecil. Tiba-tiba sang komedian melakukan kesalahan, api obor yang dia semburkan lewat bensin dari mulutnya membakar wajahnya sendiri. Orang-orang Ho Pho yang dari tadi diam, malah mereka yang mebantu sang komedian. Meskipun sambil berlarian membawa ember, mereka tertawa terpingkal-pingkal. Hal tersebut dapat terlihat pada kutipan di bawah ini.

(SM2) "Mereka melonjak-lonjak girang tapi hanya mereka yang terpikir untuk menolong komedian malang itu." (hal 137)

Berdasarkan kutipan di atas terdapat nilai karakter yang berhubungan dengan sesama. Hal ini dibuktikan bahwa ketika komedian ini sedang berada dalam kesulitan, bahkan mendapatkan musibah segera menolong tanpa pamrih. Meskipun derajat komedian lebih rendah dari orangorang yang menontonya, tetapi kewajiban sebagai sesama manusia saling tolong menolong, tidak ada yang membatasi baik itu orang tak berada maupun orang berada. Kita harus mengibaratkan jika kita berada diposisi sang komedian kemudian tidak ada yang membantunya, maka nasib buruk akan menimpa kita. Oleh karenanya selagi kita mampu dan bisa maka bantulah. 
Analisis nilai karakter yang berhubungan dengan lingkungan dan sosial dalam novel Maryamah Karpov: MimpiMimpi Lintang karya Andrea Hirata sebagai berikut.

Jambu mawar dimasukkan dalam familia jambu-jambuan, karena bijinya serupa biji jambu air. Maksudnya serupa, jika tergigit, rasa pahitnya sama, lekat di punggung lidah selama dua belas menit. Tidak pernah ada orang yang sengaja menanamkan bijinya agar cepat tumbuh. Namun tiba-tiba muncul sendiri, dengan daun-daun kecil mengkilat, di ujung pagar, di pojok pekarangan atau dekat sumur. Jika dahannya lebat tidak seorangpun berabi menebangnya. Hal tersebut dapat terlihat pada kutipan di bawah ini.

(PL1) "Lalu jika bahu-bahu dahannya mengembang, perlakuan tuan rumah padanya mirip perlakuan pada kenari dan delima, yakni tak seorangpun tega menebangnya. Anatara lain, karena pohon jambu mawar dengan murah hati sering menjulurkan lengan rendahnya yang liat untuk digantungi ayunan." (hal 113)

Berdasarkan kutipan di atas terdapat nilai karakter yang berhubungan dengan lingkungan dan sosial. Hal ini dibuktikan bahwa Dokter gigi sangat menyukai pohon jambu mawar karena menanam di pojok pekarangan halaman rumah. Bahkan sang dokter mengetahui jenis pohon ini termasuk kedalam familia jambu-jambuan karena bijinya serupa dengan biji jambu air. Tanaman merupakan mahluk hidup yang harus kita jaga dan rawat agar bertumbuh kembang dengan cara disiram setiap hari.
Analisis nilai karakter yang berhubungan dengan kebangsaan dalam novel Maryamah Karpov: Mimpi-Mimpi Lintang Karya Andrea Hirata.

Ketua Karmun beserta istri dan empat anaknya menuggu di depan gerbang. Ini adalah hari besar, ketua Karmun siap menyambut sang dokter. Putri bungsunya yang akan mengalungkan bunga ke leher dokter. Ketua Karmun tidak berhenti senyum sebab kedatangan dokter merupakan puncak prestasinya sebagai ketua kampung. Hal tersebut dapat terlihat pada kutipan di bawah ini.

(NL2) "Karena memperkirakan dokter Budi Ardiaz adalah orang jawa, maka ketua Karmun sekelurga mengenakan batik, semuanya seragaman. Orang Melayu pakai batik, elok bukan kepalang. Ia selalu membanggakan batiknya yang ia beli di Pangkal." (hal 101)

Berdasarkan kutipan di atas terdapat nilai karakter yang berhubungan dengan kebangsaan. Hal ini dibuktikan ketua Karmun yang merupakan seoarang kepala desa beserta dengan keluarganya mengenakan baju batik. Mereka berasal dari Jawa maka harus menjunjung tinggi kebudayaan leluhurnya, meskipun sekeluarga tinggal dikampung Melayu. Artinya mereka memliki jiwa nasionalisme yang tinggi dengan mempertahankan adat serta budaya yang harus selalu dilestarikan. Kecintaan terhadap budyanya tidak akan lutur karena ketua Karmun dan keluarga memeliki rasa nasionalisme yang berrti cinta terhadap apa yang sudah melekat berada dalam dirinya. 
Rancangan bahan ajar pada penelitian ini memperhatikan kriteriakriteria bahan ajar dalam pengembangannya. Hal ini dilakukan agar dapat mendukung proses pembelajaran. Kriteria yang digunakan dalam mengembangkan bahan ajar merujuk pada pendapat Harjonto dan standar perbukuan (BSNP). Kriteria tersebut mencakup empat macam yaitu aspek materi, aspek kebahasaan, dan keterbacaan serta aspek kegrafikan. Keempat aspek tersebut dijadikan angket penilaian untuk menilai penelitian bahan ajar yang teleh dikembangkan, bahan ajar yang dikembangkan dalam penelitian ini berbentuk handout.

Struktur yang digunakan dalam mengembangkan bahan ajar meliputi sampul depan, kata pengantar, daftar isi, kompetensi dasar dan inti, mata pelajaran, indikator, satuan pendidikan, latihan, referensi atau daftar pustaka. Setelah menyususun dan mengembangkan bahan ajar yang disesuaikan berdasarkan kriteriakriteria bahan ajar, tahap selanjutnya adalah melakukan validasi bahan ajar yang akan dinilai oleh validator ahli. Bahan ajar yang sudah divalidasi akan disesuaikan dengan kriteria penilaian dan ketentuan validator ahli. Hal ini dilakukan untuk menghasilkan produk akhir bahan ajar berupa handout teks novel yang sesuai dan layak untuk digunakan dalam kegiatan pembelajaran di kelas.

Produk yang dihasilkan dalam penelitian ini berupa handout bahan ajar Kompetensi Dasar 3.1 Menganalisis teks cerita sejarah, berita, iklan, editorial/opini, dan cerita fiksi dalam novel berdasarkan kaidah-kaidah baik melalui lisan maupun tulisan dan Kompetensi Dasar 4.1
Menginterpretasi makna teks cerita sejarah, berita, iklan, editorial/opini, dan cerita fiksi dalam novel berdasarkan kaidah-kaidah baik melalui lisan maupun tulisan. Bahan ajar yang dikembangkan dalam peenelitian ini mengikuti pola pengembangan Dick and Carrey. Dick and Carrey mengembangkan bahan ajar dengan sepuluh langkah.

Validasi bahan ajar berguna untuk mengetahui kelayakan bahn ajar. Uji validasi dilakukan oleh dosen pembimbing skripsi yang sudah dipastikan memiliki kemempuan menilai kelayakan bahan ajar. Tujuan validasi bahan ajar adalah untuk mengetahui hal-hal yang perlu diperbaiki dalam bahan ajar yang telah dikembangkan berdasarkan hasil analisis niali karakter pada novel Maryamah Karpov: Mimpi-mimpi Lintang karya Andrea Hirata. Bahan ajar disusun dengan memperhatikan kualifikasi HOTS.

Hasil penilaian yang telah dilakukan oleh validator ahli 1 dan validator ahli 2 adalah sebagai berikut.

\section{Validator ahli 1}

$$
\begin{aligned}
\text { Validasi } & =\mathrm{TSe} / \mathrm{TSh} \times 100 \% \\
& =40 / 48 \times 100 \% \\
& =83,33 \%
\end{aligned}
$$

Keterangan

$\mathrm{TSe}=$ Total skor empirik nilai hasil uji kompetensi yang telah dicapai

$\mathrm{TSh}=$ Total skor maksimal hasil uji kompetensi yang diharapkan dapat tercapai

Validasi

Berdasarkan data hasil validasi, dapat disimpulkan bahwa produk bahan ajar dapat dikatakan cukup valid karena mendapat skor $83,33 \%$. 
Validator ahli 2

$$
\begin{aligned}
\text { Validasi } & =\mathrm{TSe} / \mathrm{TSh} \times 100 \% \\
& =41 / 48 \% \times 100 \% \\
& =85,42 \%
\end{aligned}
$$

Keterangan

TSe $=$ Total skor empirik nilai hasil uji kompetensi yang telah dicapai

TSh $=$ Total skor maksimal hasil uji kompetensi yang diharapkan dapat tercapai

Validasi

Berdasarkan data hasil validasi, dapat disimpulkan bahwa produk bahan ajar dapat dikatakan sangat valid karena mendapatkan skor $85,42 \%$.

Selanjutnya diperoleh validasi gabungan dari kedua validator ahli dengan menggunakan rumus sebagai berikut.

$\mathrm{V}=\mathrm{V}$-ah1 + V-ah2 / 2

Keterangan

$\mathrm{V}=$ validasi gabungan

$\mathrm{V}$-ah = validasi ahli

Diketahui data:

$\mathrm{V}$-ah $1=83,33 \%$

$\mathrm{V}-\mathrm{ah} 2=85,42 \%$

Sehingga,

$\mathrm{V}=83,33 \%+85,42 \% / 2$

$\mathrm{V}=84,37 \%$

Berdasarkan perhitungan di atas, validitas bahan ajar yang dibuat memperoleh total skor sebesar 84,37\%.

Tabel 2 Kriteria Validitas

\begin{tabular}{|l|l|l|}
\hline No & $\begin{array}{l}\text { Kriteria } \\
\text { Validitas }\end{array}$ & Tingkat Validitas \\
\hline 1. & $\begin{array}{l}85,01 \%- \\
100,0 \%\end{array}$ & $\begin{array}{l}\text { Sangat valid atau dapat } \\
\text { digunakan tanpa revisi }\end{array}$ \\
\hline 2. & $\begin{array}{l}70,01 \%- \\
85,00 \%\end{array}$ & $\begin{array}{l}\text { Cukup valid atau dapat } \\
\text { digunakan namun perlu } \\
\text { direvisi kecil }\end{array}$ \\
\hline 3. & $50.01 \%-$ & Kurang valid, \\
\hline
\end{tabular}

Volume 3, Nomor 1, Januari 2021

ISSN 2655-3031 (P), 2655-7851 (O)

DOI: http://dx.doi.org/10.29300/disastra.v3i1.3306

\begin{tabular}{|l|l|l|}
\hline & $70,00 \%$ & $\begin{array}{l}\text { disarankan tidak } \\
\text { digunakan karena perlu } \\
\text { revisi besar }\end{array}$ \\
\hline 4. & $\begin{array}{l}01,00 \%- \\
50,00 \%\end{array}$ & $\begin{array}{l}\text { Tidak valid atau tidak } \\
\text { boleh digunakan }\end{array}$ \\
\hline
\end{tabular}

(Akbar, 2015: 41)

Berdasarkan tabel di atas, dapat disimpulkan bahwa bahan ajar teks novel yang telah dikembangkan termasuk dalam kategori cukup valid dan dapat digunakan namun perlu direvisi kecil sebagai bahan ajar.

\section{Simpulan}

Berdasarkan hasil analisis yang telah dipaparkan, dapat ditarik kesimpulan sebagai berikut. Pada novel Maryamah Karpov: Mimpi-mimpi Lintang karya Andrea Hirata terdapat nilai karakter dalam hubungannya dengan Tuhan, nilai karakter dalam hubungannya dengan diri sendiri, nilai karakter dalam hubungannya dengan sesama, nilai karakter dalam hubungannya dengan lingkungan dan sosial serta nilai karakter dalam hubungannya dengan kebangsaan. Nilai karakter dalam hubungannya dengan Tuhan mencakup nilai ikhtiar dan religiusitas.

Nilai karakter dalam hubungannya dengan diri sendiri mencakup nilai jujur, rajin, cerdas, bertanggungjawab, disiplin, kerja keras, percaya diri, cinta ilmu dan mandiri. Nilai karakter dalam hubungannya dengan sesama mencakup nilai bersimpati, saling membantu, sabar akan hak dan kewajiban, menghargai karya dan dan prestasi orang lain dan santun. Nilai karakter dalam hubungannya dengan lingkungan dan sosial mencakup nilai peduli lingkungan dan sosial. Nilai karakter dalam hubungannya dengan kebangsaan mencakup nasionalisme dan menghargai keberagaman. 
Hasil validasi yang telah dilakukan oleh validator ahli mendapatkan nilai validasi total sebesar $84,37 \%$ sehingga dapat dikatakan termasuk dalam kategori cukup valid dan dapat digunakan namun perlu direvisi kecil sebagai bahan ajar.

Pembahasan mengenai novel Maryamah Karpov: Mimpi-mimpi Lintang Karya Andrea Hirata berkaita dengan pengajaran novel di sekolah SMA Kelas XII terdapat dikurikulum 2013 dan KD 4.1 menginterpretasi makna teks novel baik secara lisan maupun tulisan

\section{Daftar Pustaka}

Baroroh, Kiromim. (2011). "Upaya Meningkatkan Nilai-nilai Karakter Peserta Didik melalui Penerapan Metode Role Playing". Jurnal Ekonomi dan Pendidikan, Vol.8, 2, 149-163.

Elfindri. (2014). Pendidikan Karakter: Kerangka, Metode, dan Aplikasi Untuk Pendidikan dan Professional. Jakarta: Baduose Media.

Fitria, Putri. 2015. "Nilai-nilai Karakter dalam Buku Teks Kemuhammadiyahan SMA/MA/SMK Kelas X,XI,XII Terbitan Majelis Pendidikan Dasar dan Menengah Pimpinan Wilayah Muhammadiyah Daerah Istimewa Yogyakarta". Skripsi. Universitas Islam Negeri Sunan Kalijaga.

Jamaris, M. (2013). Orientasi Baru dalam Psikologi Pendidikan. Jakarta: Yayasan Penamas murni.

Kesuma, dkk. (2011). Pendidikan Karakter Kajian Teori dan Praktik di Sekolah. Bandung: PT Remaja Rosdarya.

Komarudin, Syamsu, A. (2012). "Carachter Education and Student Social Behavior". Jurnal Of Education Learning, Vol.6, 4, 223-230.
Volume 3, Nomor 1, Januari 2021

ISSN 2655-3031 (P), 2655-7851 (O)

DOI: http://dx.doi.org/10.29300/disastra.v3i1.3306

Lickona, Thomas. (2012). Character Matters: Persoalan Karakter. Jakarta: PT Bumi Aksara.

Listyarti, Retno. (2012). Pendidikan Karakter dalam Motode Aktif, Inovatif, \& Kreatif. Surabaya: Erlangga.

Nana Sudjana. (2015). Media Pengajaran. Bandung: Sinar Biru Algesindo.

Nurgiyantoro. (2015). Teori Pengkajian Fiksi. Yogyakarta: Gajah Mada University Press.

Raharjo, Sabar Budi. (2010). "Pendidikan Karakter sebagai Upaya Menciptakan Akhlak Mulia". Jurnal Pendidikan dan Kebudayaan, Vol.16, 3, 229-238.

Salahudin, Anas dan Alkriencie, Irwanto. (2013). Pendidikan Karakter Pendidikan Berbasis \& Budaya Bangsa. Bandung: Pustaka Setia.

Sanjaya. (2016). Penilaian Hasil Proses Belajar Mengajar. Bandung: Remaja Rosdakarya.

Sugiyono. (2015a). Analisis Psikologi Tokoh Utama dalam Novel Cinta Shofia dan Kaitannya dengan Pembelajaran Sastra di SMA.

Sugiyono. (2015b). Metode Penelitian

Pendidikan (Pendekatan Kuntitatif, Kualitatif dan $R \& D)$. Bandung: CV.Alfabeta.

Wasis D. Dwiyogo. (2014). Konsep Penelitian Dan Pengembangan. Pusat Kajian Kebijakan Olahraga LEMLIT UM.

Yusuf, Muhammad. (2013). "Membentuk Karakter melalui Pendidikan Berbasis Nilai”. Jurnal Al-Ulum, Vol.13, 1, 1-24.

Lita Yolanda Aprilianti, Tati Sri Uswati, Tato Nuryanto

Nilai-Nilai Karakter dalam Novel Maryamah Karpov: Mimpi-Mimpi Lintang Karya Andrea Hirata Sebagai Bahan Ajar Novel di SMA 